\title{
\%
}

Elisa García Grande*

José Luis Echevarría Lasaga**

\section{USMCA: UNA PRIMERA APROXIMACIÓN AL NUEVO NAFTA}

En el presente artículo se analizan las principales novedades que el nuevo acuerdo comercial negociado entre Estados Unidos, México y Canadá (USMCA, por sus siglas en inglés) ha introducido en el tratado NAFTA firmado a principios de los años noventa. Se repasan los principales cambios negociados y se realiza una primera valoración del acuerdo y de lo que supone para la política comercial de Estados Unidos.

Palabras clave: acuerdo, aranceles, automóviles, comercio, cuota, importaciones, inversiones, mercado, negociación, reglas, tratado.

Clasificación JEL: F13, F15, F16, O1.

\section{Introducción}

En la campaña presidencial de 2016, la salida de Estados Unidos del North American Free Trade Agreement (NAFTA) fue una constante en los discursos del presidente Trump. En los primeros meses de su mandato, a pesar de la oposición de asociaciones empresariales, de agricultores y de la gran mayoría de representantes del Congreso, en varias ocasiones el presidente Trump estuvo cerca de anunciar la retirada de EE UU del tratado. Se dice que únicamente cuando el secretario de Agricultura,

\footnotetext{
* Consejera Jefe de la Oficina Económica y Comercial de la Embajada de España en Washington DC.

** Departamento de Proyectos Multilaterales en Fundación CEDDET.

Versión de febrero de 2019.

DOI: https://doi.org/10.32796/bice.2019.3110.6782
}

Perdue, enseñó al presidente un mapa en el que se mostraba cómo se solapaban las demarcaciones que le daban respaldo político con aquellas zonas agrícolas que más sufrirían los efectos de la salida de NAFTA este cambió de idea. En este contexto, el 18 de mayo de 2017, el presidente de EE UU pidió públicamente la renegociación del acuerdo comercial entre EE UU, México y Canadá. En agosto de ese mismo año comenzaron las negociaciones.

\section{2. ¿Ha sido NAFTA un mal acuerdo?}

Cuando se firmó el Acuerdo NAFTA, en diciembre de 1992, se creó la zona de libre comercio más grande del mundo, con una población de 450 millones de personas y unas economías que sumaban un PIB de 20,8 billones de USD. 
El efecto global de NAFTA es difícil de medir, puesto que los flujos de inversión y comercio se ven afectados por numerosos factores económicos, como el crecimiento económico, la inflación o las fluctuaciones de las monedas.

NAFTA ha sido especialmente relevante por servir de modelo para los siguientes acuerdos de libre comercio que EE UU negoció, y por ser la primera vez que se firmaba un acuerdo entre dos países ricos y un país en vías de desarroIlo. Los defensores de las negociaciones consideraban que el acuerdo permitiría crear miles de puestos de trabajo y reducir las desigualdades en la región, mientras que las voces contrarias temían importantes pérdidas de trabajo en EE UU debido al desplazamiento de la producción a México.

Desde la entrada en vigor del acuerdo, el 1 de enero de 1994, se eliminó un gran número de aranceles y el comercio entre los tres países firmantes se triplicó. En 2016 Canadá se había convertido en el principal mercado para las exportaciones de EE UU, y México, el segundo, representando los dos países el $34 \%$ de las exportaciones de EE UU. En cuanto a las importaciones estadounidenses, Canadá y México representaban el $26 \%$ del total (Anexo 1). $\mathrm{El}$ incremento en los flujos comerciales que permitió la caída de algunos costes y el aumento en la productividad llevaron a las economías a ser más competitivas, impulsando el crecimiento económico. Los sectores de EE UU más beneficiados por el acuerdo fueron agricultura, automoción y servicios, en particular salud y servicios financieros (Villareal y Ferguson, 2017). Además, el crecimiento de las exportaciones de EE UU hacia los otros dos países firmantes del acuerdo permitió la creación de cinco millones de nuevos puestos de trabajo (Baughman y Francois, 2010).

La inversión extranjera directa (IED) se multiplicó por tres: EE UU incrementó su IED en $\triangleright$

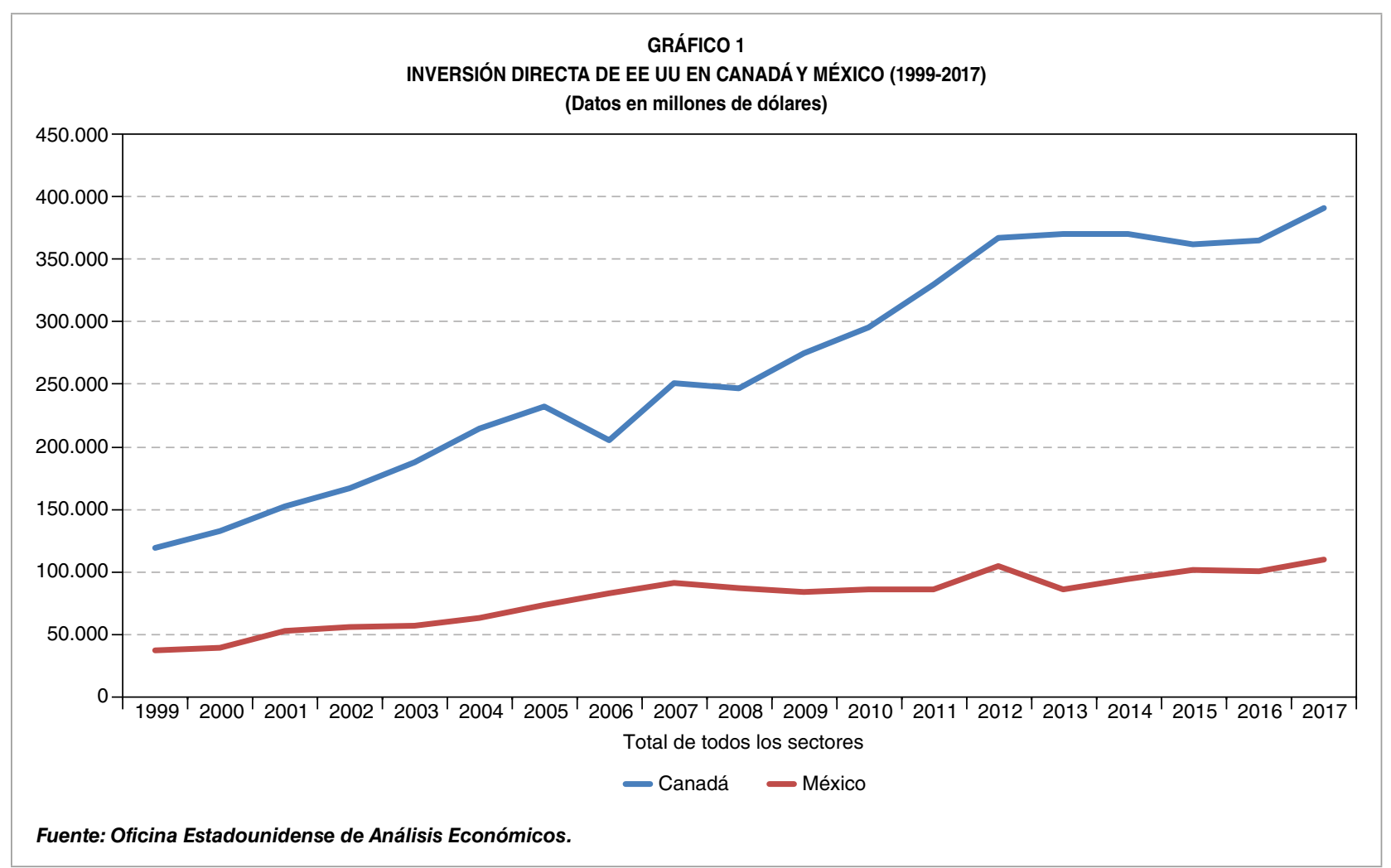


México desde 37.000 millones de USD en 1993 hasta 109.600 millones en 2017, mientras que en Canadá la inversión directa estadounidense pasó de 120.000 millones de USD en 1993 a 391.000 millones en 2017 (US Bureau of Economic Analisis, BEA).

En ese mismo periodo, la inversión directa de México en EE UU creció un $1.283 \%$, mientras que la de Canadá lo hizo un $911 \%$.

Adicionalmente, gracias a la eliminación de aranceles, NAFTA ha permitido la bajada en los precios de algunos productos clave como el petróleo, abaratando la gasolina, el transporte y también los productos agroalimentarios perecederos ${ }^{1}$.

Por último, es importante señalar que el acuerdo abrió el mercado de las compras públicas en cada uno de los tres países, incrementando la competencia y abaratando los costes.

Si bien los efectos beneficiosos del acuerdo en su conjunto son numerosos, no hay que obviar su impacto negativo en algunas áreas muy relevantes.

Aunque el efecto neto de NAFTA en el mercado de trabajo fue positivo, algunos sectores, en particular los de automoción, textil, TIC y electrodomésticos, se vieron negativamente afectados. Según un informe de 2011 del Economic Policy Institute ${ }^{2}$ (EPI), el tratado habría llevado a la pérdida de unos 683.000 puestos de trabajo (otros estudios sitúan esta cifra entre los 500.000 y 750.000 empleos), especialmente en los sectores manufactureros de California, Texas, Michigan, Ohio e Illinois. Por otra parte, la amenaza de deslocalizar inversiones hacia México frenó la adhesión sindical de los trabajadores

\footnotetext{
NAFTA. Food and Agricultural working Group. https://www. naftafoodandag.org

2 Heading south. U.S.-México trade and job displacement after NAFTA (Scott, 2011).
}

y las demandas de incrementos salariales (Brofenbrenner, 2000).

En México, la mayoría de los agricultores no pudieron hacer frente a la competencia de las importaciones de productos agroalimentarios subsidiados por la Administración de EE UU (EPI, 2011).

Muchos agricultores mexicanos desempleados acabaron trabajando en muy malas condiciones en las maquiladoras que empresas estadounidenses establecieron en la frontera con México para montar productos a bajo coste que luego eran reexportados a EE UU (el empleo en las maquiladoras se incrementó de 120.000 trabajadores en 1980 a 1,2 millones en 2006; Castillo y De Vries, 2017).

Desde el punto de vista medioambiental, NAFTA ha tenido también algunos efectos negativos, pues la competencia de las compañías estadounidenses ha llevado a los agricultores mexicanos a utilizar fertilizantes y productos químicos para hacer su producción más rentable.

Economistas y expertos en política comercial defienden la existencia de acuerdos de libre comercio (ALC) como NAFTA por fomentar el comercio y las relaciones económicas entre países, creando procesos de producción más eficientes, facilitando el acceso a bienes de consumo más baratos y mejorando los niveles de vida y condiciones de trabajo de sus poblaciones. Los críticos de estos acuerdos hacen hincapié en los efectos negativos que los ALC pueden tener, incentivando la bajada de salarios y no mejorando suficientemente ni las condiciones de trabajo ni el medioambiente de los países implicados.

El efecto neto de NAFTA en la economía de EE UU ha sido relativamente pequeño, especialmente porque el comercio total con Canadá y con México representaba menos del $5 \% \triangleright$ 
del PIB estadounidense cuando el acuerdo entró en vigor. Los efectos vinieron principalmente de la más intensa relación comercial con México, que representaba en 1994 únicamente el $1,4 \%$ del PIB de EE UU. Como en otros ALC, los ajustes y las restructuraciones a que llevan los tratados han beneficiado a unos sectores y perjudicado a otros.

\section{El nuevo acuerdo}

El 30 de septiembre de 2018, EE UU, México y Canadá alcanzaron un acuerdo para modificar NAFTA. El resultado de las negociaciones, que comenzaron en 2017 y estuvieron marcadas por grandes tensiones, se hizo oficial el 30 de noviembre en la cumbre de Buenos Aires, donde Trump, Trudeau y Peña Nieto firmaron el acuerdo USMCA ${ }^{3}$.

Tres fueron las cuestiones que suscitaron mayores discusiones durante las negociaciones: la solicitud, por parte de EE UU, de la introducción de una cláusula de rescisión del acuerdo cada cinco años, la creación de un nuevo requisito en las reglas de origen exclusivamente estadounidense, además de la eliminación completa del sistema de resolución de disputas.

Desde el inicio de las conversaciones, México y Canadá se opusieron firmemente a estas demandas, que calificaron de «líneas rojas» a no traspasar. A pesar de ello, EE UU consiguió romper ese frente común al negociar primero un acuerdo bilateral con México. Presionaba así a Canadá y le obligaba a sentarse a la mesa de negociación ante la perspectiva de quedarse fuera del acuerdo. El interés del presidente Nieto por cerrar un acuerdo antes del

3 United States-Mexico-Canada Agreement, también conocido como CUSMA en su versión canadiense y como T-MEC en su versión mexicana. fin de su mandato facilitó la estrategia estadounidense. Tras unas intensas negociaciones, el acuerdo bilateral inicial pasó a incluir a Canadá.

El acuerdo alcanzado permite recoger las demandas estadounidenses, por una parte, y el deseo de Canadá y México de mantener el acceso al mercado que garantizaba NAFTA, por otra.

\subsection{Cambios principales}

Sunset Clause

Al comienzo de las negociaciones, EE UU propuso una cláusula de suspensión por la cual el acuerdo expiraría automáticamente cada cinco años a no ser que los tres países acordaran su prórroga de manera explícita. Tanto Canadá como México la rechazaron tajantemente, alegando que generaría demasiada incertidumbre en el proceso de toma de decisiones de las empresas.

Finalmente, el acuerdo no ha recogido esta propuesta controvertida. En su lugar, se realizará una revisión del acuerdo cada seis años. Si una de las partes desea cancelar el tratado, este llegará a su fin diez años después de esa decisión. Por tanto, la suspensión definitiva del acuerdo no podrá ser efectiva antes de que transcurran dieciséis años de su vigencia.

\section{Sistema de resolución de disputas}

El sistema de resolución de disputas de NAFTA se encuentra recogido en los capítulos 11 (sistema de resolución de disputas inversor-Estado, ISDS), 19 (casos antidumping y antisubvención) y 20 (disputas Estado-Estado).

- Por lo que se refiere al capítulo 11, en un principio, EE UU, con el objetivo de $\triangleright$ 
desincentivar la inversión de empresas estadounidenses en terceros mercados, y en particular en México, planteó eliminar por completo el sistema de resolución de disputas inversor-Estado. Finalmente, en lo que concierne a las relaciones entre EE UU y México, se ha alcanzado una solución sectorializada que permite a las empresas estadounidenses que tengan contratos con el Gobierno mexicano en las áreas de la generación de energía, infraestructuras, telecomunicaciones, así como gas y petróleo, disponer de una protección absoluta, siguiendo el sistema original de NAFTA. Para el resto de casos, sin embargo, la protección estará limitada a situaciones de expropiación o ausencia de trato nacional o de nación más favorecida.

Por otra parte, Canadá y EE UU han acordado eliminar el ISDS de sus relaciones bilaterales. Se establecerá un periodo de transición de tres años, durante el cual solamente podrán optar al ISDS las inversiones realizadas cuando NAFTA estaba en vigor.

EI ISDS suscitó una gran oposición ${ }^{4}$ entre numerosos grupos de consumidores, ya que a su juicio permitía a las grandes corporaciones cuestionar legislaciones medioambientales y laborales, entre otras. La fuerte limitación del sistema supone además un gran éxito para EE UU, que considera que el ISDS debilita la soberanía nacional, además de funcionar como un seguro de riesgo político que estimula la deslocalización.

4 Canadian Opposition to Nafta's Chapter 11 Gives Trudeau Leeway: https://www.bloomberg.com/news/articles/2018-04-17/canadian-oppositionto-nafta-s-chapter-11-gives-trudeau-leeway
- Se mantiene íntegro el capítulo 19 de NAFTA, que permite a las partes cuestionar los casos de antidumping y antisubvención. Se trata de una victoria para Canadá, que quería conservarlo a pesar de la intención de EE UU de eliminarlo del nuevo acuerdo.

- Por último, el capítulo 20, que se ocupa de la resolución de disputas EstadoEstado, ha sido incluido tal y como estaba en el acuerdo NAFTA, sin mejoras en su procedimiento.

\section{Reglas de origen}

Para que un bien quedase libre de aranceles en los países miembros de NAFTA, este debía contar con cierto valor de contenido regional (RVC, por sus siglas en inglés), es decir, con cierto porcentaje de su valor producido en Norteamérica (Canadá, México o EE UU). En el caso de los automóviles, ese requisito era hasta ahora de un $62,5 \%$. Si bien durante las negociaciones EE UU intentó establecer un contenido mínimo estadounidense del 50\% y planteó aumentar a un $85 \%$ el contenido norteamericano, finalmente se ha descartado considerar el componente exclusivo de EE UU, y el norteamericano se ha incrementado al $75 \%$.

Para la aplicación de este requisito se ha previsto un periodo de transición de tres años divididos en cuatro etapas. Al final de cada etapa se incrementarán los requisitos de los umbrales para satisfacer las reglas de origen. Estas fases no podrán comenzar antes del 1 de enero de 2020 ni terminar antes del 1 de enero de 2023. De esta forma, el requisito inicial de un $62,5 \%$ de contenido regional se elevará inicialmente a un 66\%. A partir de ahí, aumentará tres puntos cada año hasta llegar al $75 \%$. 
Además, el $70 \%$ del acero y aluminio utilizado en la fabricación de coches deberá ser de origen norteamericano.

\section{Requisito salarial}

Entre un $40 \%$ y un $45 \%$ del valor del vehículo deberá ser producido por trabajadores que ganen al menos 16 dólares por hora en 2023. Se establece un periodo de transición de cinco años.

El principal afectado por este requisito será México, ya que sus trabajadores cobran una media de ocho dólares por hora, mientras que en EE UU y Canadá la media se eleva a 29 dólares por hora. La Administración Trump espera que esta provisión desanime a los fabricantes de automóviles de trasladar producción de EE UU a México.

Este requisito, inédito en acuerdos previos, sustituye de forma efectiva la demanda por parte de EE UU de un contenido exclusivamente estadounidense del $50 \%$ en las reglas de origen de los automóviles.

Analistas del sector del automóvil han señalado que esta nueva condición puede tener efectos perjudiciales tanto para los consumidores como para la industria del país, puesto que ello empujará al alza los precios de los vehícu$\operatorname{los}^{5}$ y los fabricantes se plantearán trasladar la producción a países con costes más baratos como China. Además, la cláusula salarial puede resultar poco eficaz al no estar ligada a la inflación. Un salario medio de 16 dólares por hora no significará lo mismo en 2023. Desde el USTR se ha sugerido que se aprovecharán las revisiones del acuerdo cada seis años para subsanar este tipo de cuestiones.

5 Trump's new trade deal could bring higher car prices: https://www. politico.com/story/2018/10/09/sticker-shock-trumps-new-trade-deal-couldbring-higher-car-prices-830485
Aranceles a los automóviles

En el supuesto de que EE UU imponga aranceles a las importaciones de automóviles bajo la sección $232^{6}$, Canadá y México contarán con exenciones anuales de 2,6 millones de vehículos cada uno. Esta cifra es muy superior a las importaciones estadounidenses provenientes de México en 2017 y supone más de un millón de unidades en comparación con los vehículos canadienses exportados el mismo año. Igualmente, en caso de que existan aranceles, 108.000 millones de dólares en partes de coches provenientes de México y 32.400 millones de dólares en partes canadienses quedarían exentos.

\section{Cuotas}

Las exportaciones que tengan como mínimo un contenido regional del $75 \%$ estarán sometidas a una cuota de 2,6 millones de unidades de vehículos ligeros a la exportación de México a EE UU y de Canadá a EE UU. Más allá de esa cuota, los vehículos estarían sometidos a un arancel del $2,5 \%$, si cumplen con las reglas de origen antiguas. En el caso de que, tras la investigación 232 del sector de automoción, la Administración de EE UU decida imponer un arancel, los automóviles producidos en México y Canadá por encima de esa cuota se verían sometidos al mismo. Con esta medida, EE UU busca evitar que en el caso de aplicar los aranceles de la sección 232 de la Trade Expansion Act de 1962, los automóviles de otros países $\square$

6 La sección 232 de la Ley de Expansión Comercial de 1962 (19 USC $\S 1862$ ) autoriza al secretario de Comercio a realizar investigaciones para determinar los efectos de las importaciones de cualquier artículo sobre la seguridad nacional de EE UU. El secretario de Comercio dispone de 270 días para presentar las conclusiones y las recomendaciones del Departamento al presidente. Este tiene 90 días para determinar si está de acuerdo con las conclusiones del secretario, y en ese caso aplicar las medidas necesarias para «ajustar las importaciones». 
intenten sortear esa barrera entrando a través de México. En cuanto a la asignación de cuotas a las empresas, todo apunta a que podría ser EE UU el que las asigne en función de la mayor o menor presencia de cada empresa en suelo estadounidense. Aquellas empresas con mayores inversiones obtendrían mayores cuotas.

\section{Agricultura}

USMCA proporciona a EE UU un $3,6 \%$ de acceso al mercado lácteo canadiense, en contraste con el 3,25\% negociado en el Acuerdo Transpacífico de Cooperación Económica (TPPA, por sus siglas en inglés). El antiguo sistema estaba basado en limitaciones por parte de Canadá a la importación de productos lácteos estadounidenses, así como por el apoyo gubernamental a productos canadienses, que favorecía su presencia frente a los de EE UU en los mercados internacionales.

El nuevo acuerdo supone una doble victoria para EE UU en ambos frentes, ya que fuerza a Canadá a abrir paulatinamente su mercado a la importación de productos lácteos estadounidenses, incluyendo leche líquida, nata, mantequilla, leche desnatada en polvo y queso, entre otros. Igualmente, Canadá acepta eliminar el programa que ayuda a los vendedores de ciertos productos lácteos a vender dentro y fuera del país.

\section{Nivel de minimis}

Se trata del valor máximo de un bien que puede entrar en un país sin pagar impuestos o aranceles. En el capítulo de aduanas y facilitación comercial, tanto México como Canadá se han comprometido a aumentar sus umbrales de minimis. México incrementará su nivel de minimis de 50 a 117 USD en el caso de aranceles aduaneros y 50 USD para impuestos, y Canadá aumentará su umbral para aranceles a 150 dólares canadienses (117 USD) y a 40 dólares canadienses (31 USD) para impuestos. Anteriormente, su nivel de minimis en ambos casos era de 20 dólares canadienses, siendo uno de los más bajos entre los países desarrollados. Adicionalmente, Canadá concederá al importador noventa días tras la recepción del producto para realizar el pago. Con estas medidas se pretende facilitar el comercio digital y el de las pequeñas empresas entre los tres países.

No obstante, más de una docena de asociaciones comerciales han criticado duramente una cláusula en el mismo capítulo que permitiría a EE UU reducir su nivel de minimis.

\section{Salvaguardias}

Cualquier parte que emprenda una acción de emergencia bajo el artículo xIx del GATT y el Acuerdo de Salvaguardias de la OMC deberá excluir las importaciones de bienes de los otros miembros del acuerdo, a no ser que:

- Las importaciones del país miembro constituyan una parte importante de las importaciones totales.

- Las importaciones del país miembro contribuyan de forma significativa al daño o a la amenaza del mismo causado por las importaciones.

Igualmente, EE UU se abstendrá de imponer aranceles, bajo la sección 232, a Canadá y México durante los sesenta días posteriores a su imposición general. A lo largo de este periodo de tiempo, EE UU mantendrá negociaciones con las partes para alcanzar una solución apropiada basándose en las tendencias del sector y en la historia comercial entre $D$ 
ambos países. Canadá y México podrán responder con represalias equivalentes si la acción emprendida por EE UU bajo la sección 232 es inconsistente con los compromisos del país suscritos en USMCA, NAFTA o la OMC.

\section{Medidas comerciales correctivas}

(trade remedies)

Se incluye un novedoso sistema de cooperación para compartir información por el cual los países miembros deben intercambiar datos aduaneros sobre importaciones, exportaciones y transacciones en tránsito. El objetivo, según el acuerdo, es combatir el fraude a las medidas antidumping, antisubvención y de salvaguardia. No obstante, numerosos expertos en la materia ven preocupante la obligación de compartir este tipo de información con EE UU, dada su fijación por los déficits comerciales.

\section{Medio ambiente (capítulo 24)}

Numerosos grupos ecologistas han criticado el lenguaje no ejecutable de USMCA, al que acusan de suponer un retroceso en comparación con los compromisos medioambientales negociados en otros acuerdos anteriores. En efecto, desde el compromiso del 10 de mayo entre la Administración Bush y el Partido Demócrata, EE UU se comprometió a incluir en sus acuerdos de libre comercio futuros un conjunto de siete acuerdos multilaterales de medio ambiente (multilateral environmental agreements). En los ALC firmados con Perú, Colombia, Panamá y Corea del Sur se siguió este compromiso. Los grupos ecologistas han argumentado, sin embargo, que en USMCA se opta por un enfoque menos ambicioso, basado en el capítulo ambiental del TPP. De los siete acuerdos medioambientales que deben ser referenciados solamente uno cuenta con lenguaje de ejecución estándar (standard enforcement language). Dos acuerdos contienen lenguaje no vinculante y cuatro ni siquiera son mencionados?

\section{Propiedad intelectual y datos}

Se prohíben los requisitos de almacenamiento de datos locales. Se trata de un tema del que EE UU lleva años quejándose. Critica el sistema actual de gestión de datos en Canadá que, en la práctica, fuerza a las empresas estadounidenses que quieran ganar contratos allí a mantener sus datos en ese país. De esta forma, los proveedores estadounidenses de clouding quedan fuera del proceso de contratación pública canadiense. Además, el acuerdo incluye una protección de datos de diez años para los medicamentos biológicos (la ley canadiense contempla ocho años) y una ampliación de los productos elegibles para optar a esta protección.

En lo que concierne a la regulación de la protección del copyright y a la determinación de responsabilidades de los proveedores de servicios de Internet (ISP, por sus siglas en ingles), no se incluirán finalmente las excepciones de uso justo (fair use exceptions). En su lugar, se establece un sistema basado en la notificación y retirada (notice and takedown), basado en el modelo estadounidense. Mediante este sistema, una vez que el contenido infractor es notificado al ISP, este debe retirarlo y asegurarse de que no reaparezca en su plataforma. Sin embargo, no se exigirá a Canadá que modifique su sistema de responsabilidad de los ISP (liability system). Canadá podrá, por tanto, $D$

7 Se incluye lenguaje no vinculante para el Protocolo de Montreal sobre la Protección de la Capa de Ozono y la Convención sobre la Descarga de Deshechos. No se menciona la Convención sobre el Atún Tropical, la Convención sobre los Humedales, la Convención Internacional de las Ballenas y la Convención para la Conservación de Recursos Vivos Marinos Antárticos. 
conservar su sistema notice and notice, en el que los ISP pueden quedar exentos de responsabilidad ante una infracción del copyright, incluso si no retiran la obra infractora tras ser notificados (a diferencia del sistema notice and takedown, en que los ISP deben retirar la obra si quieren optar a la exención). Otros puntos acordados se incluyen a continuación:

- Se otorgará trato nacional sin limitaciones al copyright y derechos asociados de los creadores estadounidenses de tal forma que no carezcan de las mismas protecciones que los creadores domésticos reciben en mercados extranjeros.

- Se establece un copyright mínimo que cubra la vida del autor y 70 años adicionales o 75 años tras la primera publicación autorizada de trabajos con una duración del copyright no basada en la vida de la persona.

\section{Comercio digital}

- Se imponen límites más elevados al comercio online que puede llevarse a cabo libre de impuestos (aumento del umbral de minimis).

- Se prohíben los derechos arancelarios y otras medidas discriminatorias sobre los productos digitales distribuidos electrónicamente (e-books, vídeos, música, software, juegos, etcétera).

- Se tomarán medidas para garantizar la transferencia transfronteriza de datos y se minimizarán los límites a la localización y procesamiento de los datos.

- Se limitará la habilidad del Gobierno para requerir la revelación del código fuente y los algoritmos con el fin de proteger la competitividad de los proveedores digitales.

\section{Servicios financieros}

Se adoptarán diversas medidas para liberalizar el sector, entre las que destaca el tratamiento nacional para garantizar que los proveedores de servicios financieros estadounidenses reciben el mismo tratamiento que los proveedores locales.

Igualmente, se ofrecerá acceso de mercado mediante la prohibición de ciertas restricciones cuantitativas y numéricas que pudieran limitar el negocio de los proveedores estadounidenses.

\section{Indicaciones geográficas}

Se trata de un tema de especial relevancia para la Unión Europea por sus posibles repercusiones en las relaciones comerciales. Por primera vez se han establecido nuevas regulaciones sobre las indicaciones geográficas de los quesos. Se establecerá un mecanismo para consultar los productos sujetos a indicaciones geográficas según los acuerdos internacionales. Se pretende aumentar la transparencia, además de añadir factores adicionales a tener en cuenta para determinar si el nombre de un producto se enmarca dentro de las indicaciones geográficas o si, por el contrario, es un nombre común.

Cualquier aplicación a una indicación geográfica debe incluir procedimientos para denegar o cancelar dicha protección. Uno de los motivos que pueden emplearse para denegarla es que la indicación sea un término de lenguaje común para el nombre común del bien en cuestión.

Se establece un proceso para reconocer indicaciones geográficas consistente en un $\triangleright$ 
periodo de aplicación, de comentarios públicos y de decisiones escritas.

En un acuerdo paralelo, México se compromete a no restringir el acceso a su territorio a ciertos quesos estadounidenses que EE UU considera nombres comunes. Estos productos incluyen el queso brie, cottage, gouda, mozzarella, pepper Jack, ricota y swiss, entre otros ${ }^{8}$, y podrán ser comercializados sin ninguna restricción tanto en México como en EE UU.

En otro acuerdo paralelo, Canadá se compromete a eliminar la ley que impide en la Columbia Británica que el vino importado se venda al lado del vino doméstico canadiense.

\section{Manipulación de divisas (currency chapter)}

Se incluye un capítulo de políticas macroeconómicas y tipos de cambio que incorpora compromisos para abstenerse de realizar devaluaciones competitivas y manipular los tipos de cambio. Este capítulo no tiene precedentes en ningún acuerdo previo y se espera que refuerce la estabilidad macroeconómica y de los tipos de cambio. Cada parte del acuerdo confirma que se encuentra sujeta a los artículos del FMI para evitar manipular los tipos de cambio o el sistema monetario internacional para prevenir ajustes de la balanza de pagos u obtener una ventaja competitiva injusta. Se establecerá un Comité Macroeconómico para supervisar la aplicación del capítulo. También se incluyen procedimientos de resolución de disputas en caso de que un miembro no haya cumplido con sus obligaciones.

Aunque la inclusión de este capítulo ha sido aplaudida por numerosos grupos y asociaciones, existen críticas por parte de los Comités Asesores, que cuestionan su efectividad. Esto

8 List of cheese names: https://ustr.gov/sites/default/files/files/ agreements/FTA/USMCA/Side \%20Letter $\% 20-\% 20$ US $\% 20 M X \% 20$ Cheese\%20Names.pdf es debido a que México ya permite que su divisa flote libremente y pone a disposición del público la información requerida. Igualmente, el capítulo no incluye ningún tipo de acción conjunta entre los países del acuerdo para combatir la manipulación de divisas de terceros países como China. También se critica que no se haya identificado esta manipulación como una forma de subsidio.

\section{Empresas públicas}

A diferencia de NAFTA, en que las empresas públicas (SOE, por sus siglas en inglés) formaban parte del capítulo de políticas de competencia, USMCA incluye un capítulo específico para esta temática. Es evidente la importante influencia del TPP en la redacción del capítulo. Del mismo modo, se ha ampliado considerablemente la definición de empresa pública, de tal forma que incluya provisiones sobre la propiedad minoritaria o indirecta.

Una SOE, por tanto, es toda aquella empresa que participe en actividades comerciales y en cuyo acuerdo una de las partes:

- Posea directa o indirectamente más del $50 \%$ del capital social.

- Controle, a través de participaciones accionariales directas o indirectas, más del $50 \%$ de los derechos de voto.

- Pueda tomar el control de la empresa a través de cualquier otra participación accionarial, incluyendo la propiedad indirecta o minoritaria.

- Pueda nombrar una mayoría de los miembros de la junta directiva o cualquier otro órgano equivalente.

Tanto el comité asesor encargado de analizar este capítulo como fuentes del sector $\triangleright$ 
privado han aplaudido esta definición. Se trata de un modelo a seguir en futuros acuerdos comerciales y sienta un precedente. Eventualmente, podría ayudar a combatir las prácticas comerciales desleales por parte de China. El reto, sin embargo, reside en asegurarse de que se cumplen las nuevas regulaciones.

\section{China}

El acuerdo incluye una cláusula (artículo 32.10) que busca impedir que México y Canadá firmen un tratado de libre comercio con China. Según el artículo, si cualquier parte suscribe un ALC con un país que no sea una economía de mercado, tendrá que notificar primero al resto de países y permitirles revisar el texto del acuerdo. Las partes podrán entonces anular USMCA a favor de un acuerdo bilateral. Para que un país sea considerado como no economía de mercado es preciso que en el momento en que se firme USMCA al menos una de las partes haya determinado que el país en cuestión no es una economía de mercado y que ninguna de las partes tenga un ALC con ese país. Aunque el nombre de China no aparece en la provisión, el USTR declaró, el 1 de octubre de 2018, que si cualquiera de los países de USMCA suscribe un ALC con China, EE UU solicitaría revisar el acuerdo. Se espera que la Administración Trump trate de incorporar esta cláusula en los futuros acuerdos comerciales que negocie. Cabe destacar que el artículo concierne solamente a los ALC, por lo que no impide la negociación de acuerdos bilaterales de inversiones con el país asiático.

La Administración canadiense no ha considerado esta cláusula problemática, puesto que USMCA ya incluye un mecanismo de rescisión de seis meses, similar al de NAFTA, y la cláusula de China es vista como un simple requisito de transparencia. México tampoco se ha opuesto a esta provisión.

\section{Capítulo laboral}

Se ha incluido un anexo sobre representación de los trabajadores en la negociación colectiva en México por el cual el país se compromete a emprender acciones legislativas específicas para garantizar el reconocimiento efectivo del derecho a la negociación colectiva. Igualmente, México tendrá que facilitar a los trabajadores la constitución de sindicatos y la adhesión a los mismos.

\section{Camiones}

El comercio transfronterizo entre México y EE UU mediante camiones fue uno de los aspectos más controvertidos del antiguo NAFTA. Aunque el acuerdo autorizó una aplicación gradual, EE UU retrasó reiteradamente el cumplimiento de este compromiso con México. Estos retrasos llevaron a México a imponer aranceles como represalia de más de 2.000 millones USD en exportaciones estadounidenses ${ }^{9}$.

Un anexo al acuerdo permitirá a EE UU limitar la distancia que los camiones mexicanos pueden recorrer para transportar bienes dentro de su territorio. Se trata de una victoria para los sindicatos Teamsters y la Owner-Operator Independent Drivers Association (OOIDA), que durante años han solicitado limitaciones a las concesiones de permisos a compañías mexicanas para operar más allá de las zonas comerciales estadounidenses.

El anexo especifica que EE UU se reserva el derecho de limitar las concesiones a personas mexicanas para proveer de servicios $\triangleright$

9 México levantó los aranceles en 2011, cuando EE UU comenzó un programa piloto. 
transfronterizos de camiones de larga distancia a las afueras de zonas comerciales fronterizas en EE UU. Estas limitaciones están permitidas si se estima que son necesarias para solucionar un daño material o la amenaza de daño material a proveedores, operadores o conductores estadounidenses. Se entiende «daño material» como una pérdida significativa en la cuota de mercado en EE UU de las empresas de camiones estadounidenses, causado por o atribuible a personas mexicanas.

Se estima que más de 385.000 millones de USD se transportan anualmente entre México y EE UU mediante camiones.

Las zonas comerciales se extienden $25 \mathrm{mi}-$ llas al norte en los estados de California, Nuevo México y Texas, y 75 millas en Arizona.

Este anexo ha sido duramente criticado por numerosas asociaciones mexicanas, que señalan que no se ha conseguido un tratamiento similar para las empresas estadounidenses en suelo mexicano. No obstante, cabe destacar que ninguna de las empresas mexicanas que actualmente operan la frontera se verá inmediatamente afectada, ya que el anexo les concede una exención temporal.

\section{Valoración}

NAFTA puso en pie las condiciones necesarias para desarrollar sofisticadas cadenas de valor que han permitido a las empresas de los tres países ahorrar costes y ser más innovadoras.

Los empresarios de EE UU, Canadá y México tomaron en su día decisiones de localización de sus plantas de producción en función de las ventajas ofrecidas por el acuerdo y realizaron significativas inversiones basadas en el clima de certidumbre existente en las relaciones comerciales al amparo de NAFTA.
En este contexto, cualquier modificación de las condiciones de NAFTA afectará al valor de las plantas y a las cadenas de valor establecidas en Norteamérica, generando mayores costes y, en algunos casos, provocando incluso la disrupción de las operaciones. La interrelación entre múltiples compañías previsiblemente tendría un efecto dominó que exigiría la reorganización de las cadenas de aprovisionamiento.

El caso más claro es el del sector de automoción, piedra angular del nuevo tratado, que se verá afectado tanto por las nuevas reglas de origen, que se incrementarán paulatinamente hasta un $75 \%$ en 2023 , como por los nuevos aspectos laborales incluidos en el acuerdo.

Cuando el acuerdo USMCA entre en vigor, en la construcción de un automóvil para pasajeros, por ejemplo, deberán cumplirse cuatro requerimientos: el $75 \%$ del valor del coche deberá tener un origen regional, algunas partes centrales del vehículo deberán tener su origen también en la región USMCA (entre un 65 y $70 \%$ en función de si es considerada parte fundamental, principal o complementaria), el productor deberá utilizar un $70 \%$ de acero y aluminio proveniente de Norteamérica y además el $40 \%$ del coste del trabajo deberá provenir de mano de obra contratada con «sueldos elevados».

Por otra parte, la complejidad de las reglas de origen que el nuevo acuerdo introduce hace que muchos pequeños y medianos proveedores de componentes se encuentren con dificultades e importantes costes adicionales para hacer frente a las obligaciones administrativas de trazabilidad de cada una de las piezas utilizadas en el proceso de producción.

El pasado 15 de noviembre, la International Trade Commission (ITC) ${ }^{10}$ organizó una audiencia para recabar información y valorar el $D$

10 https://www.usitc.gov/research_and_analysis/ongoing/fr_notice_ inst_signed_usmca.pdf 
efecto económico que el acuerdo USMCA tendrá en EE UU y elaborar así el informe de impacto que la Autoridad de Promoción Comercial (TPA, en sus siglas en inglés) exige. Durante la sesión intervinieron los principales actores del sector de automoción ${ }^{11}$ y la Comisión intentó determinar si las nuevas reglas de origen son factibles de aplicar y si las empresas deberán realizar cambios sustanciales en sus procesos de producción para poder adaptarse a ellas.

Existe un cierto consenso dentro del sector para mencionar la identificación del origen de la mano de obra a lo largo de la cadena de producción como una de las más complejas dentro de las nuevas reglas. Además, las diferentes asociaciones implicadas insisten en la necesidad de tener en cuenta en el ejercicio de valoración de USMCA los aranceles al acero y al aluminio en el marco de la sección 232 que siguen vigentes y que afectan directamente al sector y a su competitividad.

De no existir los aranceles al aluminio y al acero, el sector tiene cierta confianza en poder ajustar las cadenas de producción a las nuevas reglas de origen, no sin antes haber puesto en marcha completos programas de adaptación y capacitación de los equipos de trabajo.

La amenaza de aranceles adicionales a los coches y componentes importados de terceros países bajo la sección 232 complica sobremanera el estudio de impacto del USMCA en las cadenas de producción y hace difícil poder determinar con fiabilidad si las nuevas reglas de origen afectarán a la localización de las plantas de producción. En una primera aproximación a la cuestión, parece que todo dependería de si las nuevas reglas suponen un incremento de costes por encima del arancel equivalente del 2,5\% (nación

11 El American Automotive Policy Council, La American International Dealers Association, la Alliance of Automotive Manufacturers y la Association of Global Automakers, entre otros. más favorecida). Si la complejidad en los nuevos costes administrativos y los ajustes en la cadena de valor llevan a un incremento en los costes de producción por encima del $2,5 \%$, es razonable pensar que las empresas opten por trasladar su producción fuera de EE UU.

Por último, es importante destacar que USMCA no excluye formalmente a las exportaciones, de automóviles y componentes de México y Canadá, de la posibilidad de verse sometidos a aranceles derivados de la investigación abierta por el Departamento de Comercio al sector de automoción en el marco de la sección 232 $y$, en su lugar, incluye un intercambio de cartas que tienen por objeto intentar aislar a estos dos países del impacto de una posible imposición de aranceles. $\mathrm{Si}$, a cambio del incremento en los costes de producción derivado de las nuevas reglas, Canadá y México evitan ser penalizados con aranceles del $25 \%$, las compañías considerarían las nuevas reglas de origen y de contratación un mal menor y preferirán someterse a ellas.

En estas condiciones, las grandes empresas del sector de automoción se verán en la tesitura de elegir entre una combinación de las siguientes estrategias: absorber los mayores costes en detrimento de su margen, renegociar los contratos con sus proveedores y trasladarles el incremento de costes o incrementar los precios finales y trasladar el coste a los consumidores. Es muy plausible, también, una combinación de las tres estrategias.

\section{Conclusión}

El acuerdo USMCA fue firmado el pasado 30 de noviembre por los presidentes Trump y Peña Nieto, y por el primer ministro Trudeau, pero todavía está pendiente de ratificación por los poderes legislativos de los tres países. $\quad \square$ 
Según establece la Autoridad de Promoción Comercial, la International Trade Commission (ITC) debe realizar un informe sobre el posible impacto de los acuerdos de libre comercio que tiene que ser presentado, ante el Congreso de EE UU, 105 días después de que el país firme un acuerdo. En el caso de USMCA, el informe tendría que ser presentado el 15 de marzo.

Una vez el Congreso disponga de toda la documentación para su estudio y toma de decisión, no está claro qué es lo que puede suceder con este nuevo tratado, puesto que existen algunas objeciones al mismo, en particular desde el Partido Demócrata. Se está afianzando la exigencia de introducir mecanismos que garanticen el estricto cumplimiento de algunas de las medidas establecidas, en particular en lo que se refiere a estándares medioambientales y laborales ${ }^{12}$. A este respecto el responsable del USTR, Robert Lighthizer, ha hablado de la posibilidad de utilizar la sección 301 del Trade Act de 1974 para imponer penalizaciones unilaterales a México o Canadá si se viola el acuerdo comercial. Esta posibilidad ha despertado numerosas críticas, puesto que llevaría a los países castigados a responder con medidas de represalia y penalizaría el acceso al mercado regional.

Por otra parte, tanto republicanos como demócratas coinciden en señalar que el acuerdo no debería ratificarse mientras sigan vigentes los aranceles al acero y al aluminio establecidos por la Administración Trump bajo la sección 232 de la Trade Expansion Act de 1962.

Las formas de negociación y el continuo ambiente de amenaza en que se ha desarrollado el nuevo acuerdo NAFTA hacen de este un

\footnotetext{
12 Son de especial relevancia las reformas que la Administración de México deberá realizar en el ámbito laboral para garantizar el derecho de los trabajadores a participar en actividades concertadas para la negociación o protección colectiva, así como a organizar, formar y unirse al sindicato de su elección. Se deberán prohibir también las interferencias de los patrones en las actividades sindicales y la coerción o discriminación a los trabajadores por implicarse en una actividad sindical.
}

tratado muy particular y diferente de anteriores acuerdos de libre comercio. Destaca el hecho de que en todo el acuerdo no se hace mención al libre comercio y que, por el contrario, unas medidas de protección comercial como los aranceles son sustituidas por otras, las cuotas, incluso entre los socios del acuerdo. Existe, pues, una voluntad clara de no profundizar en una mayor integración comercial y, por el contrario, replegarse en los mercados nacionales, promover el insourcing y la producción local en EE UU. Es preocupante el uso que se hace en el acuerdo de la sección 232 como arma de negociación y la aceptación por parte de los socios de EE UU de la introducción de cuotas (cartas anexas al acuerdo en el sector automoción).

A la hora de juzgar el éxito del nuevo acuerdo, tanto desde el lado mexicano como desde el canadiense coinciden en señalar que no hay que comparar los resultados del acuerdo con las expectativas que se podían tener al inicio de la negociación, sino más bien con la alternativa que parecía desprenderse de los diferentes gestos de la Administración Trump, esto es, una guerra comercial con EE UU y, con ello, la pérdida de mercado, de un clima favorable a los negocios y oportunidades de crecimiento y empleo que tanto había costado construir en el pasado.

EE UU aspira a que USMCA se convierta en un modelo de acuerdo que sirva de base para futuras negociaciones comerciales. Este acuerdo ha buscado avanzar en tres elementos clave: el «reequilibrio» de las relaciones comerciales de EE UU, la inclusión de nuevas cuestiones propias del siglo xxI, como la propiedad intelectual o el comercio digital, y la lucha contra prácticas comerciales desleales. En este tratado queda ya plasmada, sin ningún tipo de resquicio a la duda, la voluntad por parte del presidente Trump de convertir el comercio administrado en su principal herramienta de política comercial. 


\section{Bibliografía}

[1] Baughman, L., y Francois, J. (2010). Opening Markets, Creating Jobs: Estimated U.S. Employment Effects of Trade with FTA Partners. US Chamber of Commerce. Recuperado de www.uschamber.com

[2] Brofenbrenner, K. (2000). Uneasy Terrain: The impact of capital mobility on workers, wages, and union organizing. Cornell University. ILR School. Recuperado de https://digitalcommons.ilr.cornell.edu/reports/3/

[3] Castillo, J. C., y De Vries, G. (2017). The domestic content of Mexico's maquiladora exports: A long-run perspective. The journal of International Trade and Economic Development, 27(2), 200-219.

[4] Scott, R. (2011). Heading south. U.S.-México trade and job displacement after NAFTA. Economic Policy Institute. Recuperado de https://www.epi.org

[5] Villareal, M. A., y Fergusson, I. F. (2017). The North American Free Trade Agreement (NAFTA) (CRS Report R42965). Washington, D.C.: Congressional Research Service. Recuperado de www.crs.gov 
ANEXO 1

EXPORTACIONES-IMPORTACIONES DE EE UU POR PAÍSES. OCTUBRE DE 2018

(En millones de dólares)

\begin{tabular}{|c|c|c|c|c|c|c|c|c|}
\hline \multirow[b]{2}{*}{ Áreas geográficas } & \multicolumn{4}{|c|}{ Exportaciones } & \multicolumn{4}{|c|}{ Importaciones } \\
\hline & $\begin{array}{c}\text { Ene-oct } \\
2017\end{array}$ & $\begin{array}{c}\text { Ene-oct } \\
2018\end{array}$ & $\%$ total & $\% 18 / 17$ & $\begin{array}{c}\text { Ene-oct } \\
2017\end{array}$ & $\begin{array}{c}\text { Ene-oct } \\
2018\end{array}$ & $\%$ total & $\% 18 / 17$ \\
\hline Norteamérica & 435.926 & 474.190 & 34,0 & 8,8 & 509.387 & 558.930 & 26,1 & 9,7 \\
\hline Canadá & 233.914 & 251.609 & 18,0 & 7,6 & 247.901 & 269.197 & 12,6 & 8,6 \\
\hline México & 202.012 & 222.580 & 15,9 & 10,2 & 261.486 & 289.733 & 13,5 & 10,8 \\
\hline Europa & 275.506 & 309.859 & 22,2 & 12,5 & 415.227 & 475.606 & 22,2 & 14,5 \\
\hline Unión Europea & 234.903 & 265.672 & 19,0 & 13,1 & 355.787 & 404.793 & 18,9 & 13,8 \\
\hline Austria & 3.685 & 2.900 & 0,2 & $-21,3$ & 9.555 & 11.074 & 0,5 & 15,9 \\
\hline Bélgica & 25.170 & 26.450 & 1,9 & 5,1 & 12.455 & 14.391 & 0,7 & 15,5 \\
\hline República Checa & 1.835 & 2.603 & 0,2 & 41,9 & 3.778 & 4.173 & 0,2 & 10,5 \\
\hline Finlandia & 1.311 & 1.623 & 0,1 & 23,8 & 4.811 & 6.108 & 0,3 & 27,0 \\
\hline Francia & 27.934 & 30.295 & 2,2 & 8,5 & 39.806 & 43.475 & 2,0 & 9,2 \\
\hline Alemania & 44.490 & 48.313 & 3,5 & 8,6 & 96.708 & 104.804 & 4,9 & 8,4 \\
\hline Hungría & 1.601 & 1.427 & 0,1 & $-10,9$ & 4.161 & 4.184 & 0,2 & 0,6 \\
\hline Irlanda & 8.549 & 9.085 & 0,7 & 6,3 & 40.068 & 48.058 & 2,2 & 19,9 \\
\hline Italia & 15.243 & 19.695 & 1,4 & 29,2 & 40.255 & 45.357 & 2,1 & 12,7 \\
\hline Países Bajos & 34.608 & 40.755 & 2,9 & 17,8 & 14.370 & 19.504 & 0,9 & 35,7 \\
\hline Polonia & 3.725 & 4.573 & 0,3 & 22,8 & 5.832 & 6.744 & 0,3 & 15,6 \\
\hline España & 9.379 & 10.974 & 0,8 & 17,0 & 12.679 & 14.818 & 0,7 & 16,9 \\
\hline Suecia & 3.006 & 3.608 & 0,3 & 20,0 & 8.715 & 9.543 & 0,4 & 9,5 \\
\hline Reino Unido & 46.549 & 54.757 & 3,9 & 17,6 & 43.754 & 50.152 & 2,3 & 14,6 \\
\hline Otros países de la UE & 7.818 & 8.615 & 0,6 & 10,2 & 18.840 & 22.408 & 1,0 & 18,9 \\
\hline Noruega & 4.697 & 4.638 & 0,3 & $-1,3$ & 4.310 & 5.546 & 0,3 & 28,7 \\
\hline Rusia & 5.702 & 5.662 & 0,4 & $-0,7$ & 14.153 & 17.595 & 0,8 & 24,3 \\
\hline Suiza & 17.989 & 19.675 & 1,4 & 9,4 & 29.604 & 34.108 & 1,6 & 15,2 \\
\hline Países de la cuenca del Pacífico & 325.069 & 344.312 & 24,7 & 5,9 & 712.509 & 765.098 & 35,8 & 7,4 \\
\hline Australia & 20.362 & 21.023 & 1,5 & 3,2 & 8.438 & 8.466 & 0,4 & 0,3 \\
\hline China & 103.484 & 102.494 & 7,3 & $-1,0$ & 412.876 & 446.964 & 20,9 & 8,3 \\
\hline Indonesia & 5.598 & 6.960 & 0,5 & 24,3 & 16.907 & 17.597 & 0,8 & 4,1 \\
\hline Japón & 55.450 & 61.383 & 4,4 & 10,7 & 113.001 & 117.573 & 5,5 & 4,0 \\
\hline Malasia & 11.047 & 10.739 & 0,8 & $-2,8$ & 30.605 & 32.675 & 1,5 & 6,8 \\
\hline Filipinas & 6.776 & 7.214 & 0,5 & 6,5 & 9.650 & 10.300 & 0,5 & 6,7 \\
\hline Nuevos países industrializados* & 134.499 & 122.352 & 10,5 & 9,9 & 131.522 & 121.031 & 6,7 & 8,7 \\
\hline América del Sur y Central & 123.585 & 135.224 & 9,7 & 9,4 & 96.759 & 102.771 & 4,8 & 6,2 \\
\hline Argentina & 8.043 & 8.233 & 0,6 & 2,4 & 3.940 & 4.009 & 0,2 & 1,8 \\
\hline Brasil & 30.679 & 33.290 & 2,4 & 8,5 & 24.318 & 26.381 & 1,2 & 8,5 \\
\hline Chile & 11.057 & 12.541 & 0,9 & 13,4 & 8.977 & 9.886 & 0,5 & 10,1 \\
\hline Colombia & 11.131 & 12.268 & 0,9 & 10,2 & 11.222 & 11.532 & 0,5 & 2,8 \\
\hline Otros & 7.818 & 8.615 & 0,6 & 10,2 & 18.840 & 22.408 & 1,0 & 18,9 \\
\hline OPEC & 48.568 & 47.651 & 3,4 & $-1,9$ & 60.420 & 67.815 & 3,2 & 12,2 \\
\hline África & 18.383 & 21.272 & 1,5 & 15,7 & 27.481 & 30.422 & 1,4 & 10,7 \\
\hline Otros países & 58.751 & 70.176 & 5,0 & 19,4 & 140.859 & 151.063 & 7,1 & 7,2 \\
\hline Total & 1.280 .398 & 1.395 .797 & 100,0 & 9,0 & 1.949 .738 & 2.138 .574 & 100,0 & 9,7 \\
\hline
\end{tabular}

